"Improving a graduate Marketing Management course: a case study with input from students"

\begin{tabular}{|c|c|}
\hline AUTHORS & $\begin{array}{l}\text { Khalid M. Dubas E https://orcid.org/0000-0001-5271-4484 } \\
\text { Maria D. Cerra }\end{array}$ \\
\hline ARTICLE INFO & $\begin{array}{l}\text { Khalid M. Dubas and Maria D. Cerra (2016). Improving a graduate Marketing } \\
\text { Management course: a case study with input from students. Innovative Marketing } \\
\text {, 12(3), 6-18. doi:10.21511/im.12(3).2016.01 }\end{array}$ \\
\hline DOI & http://dx.doi.org/10.21511/im.12(3).2016.01 \\
\hline RELEASED ON & Wednesday, 28 December 2016 \\
\hline JOURNAL & "Innovative Marketing " \\
\hline FOUNDER & LLC "Consulting Publishing Company "Business Perspectives" \\
\hline & 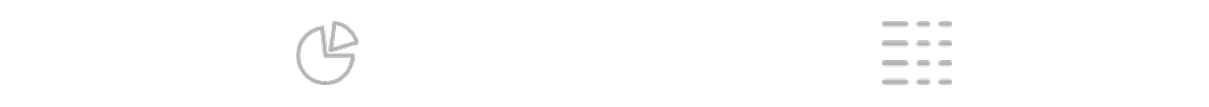 \\
\hline NUMBER OF REFERENCES & NUMBER OF FIGURES \\
\hline
\end{tabular}

(C) The author(s) 2022. This publication is an open access article. 
Khalid M. Dubas (USA), Maria D. Cerra (USA)

\title{
Improving a graduate Marketing Management course: a case study with input from students
}

\begin{abstract}
The authors develop a conceptual model of a student's course satisfaction based on several factors that influence course learning outcomes and student's satisfaction. This model provides a general framework to guide course design and to influence students' course outcomes. A Marketing Management course is a part of a typical MBA program. This paper presents ideas for enhancing the design and teaching of such a course in an online setting based on teaching experience at MBA programs at several universities in the USA. Suggestions are also presented for improving team productivity and the quality of team output in an online setting. As a case study, the authors discuss a graduate Marketing Management course that was taught at a private US university in summer 2016. They discuss the design, teaching and strategies for enhancing student learning outcomes in this course. Suggestions by students to improve this course are also presented.
\end{abstract}

Keywords: marketing, student's satisfaction, higher education, universities.

JEL Classification: M3, M1, I23.

\section{Introduction}

Many students pursue an MBA degree at universities all over the world. Many students in these programs have a previous degree in business administration, but many students from non-business backgrounds also pursue these degrees. Universities offer MBA degrees in traditional 16-week format or in a shorter, more accelerated format. Courses may be offered in a traditional face-to-face format, in online format, or in a hybrid format. Students may be traditional full-time students or they may be part-time students who take one or two MBA courses per semester. Teaching these courses involves many challenges due to students' diverse backgrounds, diverse course delivery formats, accelerated course formats, large class sizes, and teamwork requirements.

Some studies present methods for designing optimal courses (Katzenstein et al., 1994; Dubas \& Strong, 1993) or enhancing existing courses (Dubas et al., 2016) while others have offered guidelines for enhanced online discussion (Favor \& Kulp, 2015) and rubrics for assessment of participation in online discussion (Hazari, 2004; Kayler \& Weller, 2007; Alden, 2011).

We present here a model for student's course satisfaction based on several factors. Next, we present a case study of teaching a Marketing Management course and present strategies and tools to enhance students' course outcomes. This article presents ideas for improving team participation and the quality of output. This case study of a graduate course in Marketing Management requires student teams to

(C) Khalid M. Dubas, Maria D. Cerra, 2016.

Khalid M. Dubas, Dr., Professor of Marketing, University of Mount Olive, USA.

Maria D. Cerra, University of Mount Olive \& Wayne Community College, NC, USA. write a marketing plan over the course of an accelerated 7-week semester. Strategies used by the instructor and students to improve team productivity in this class project are also presented.

\section{A model of students' course satisfaction}

Many factors influence students' satisfaction with a particular course. One critical aspect of students' satisfaction concerns with the fact that course outcomes, as in many services, are jointly produced by the instructor and students. If team work is involved, then the students' course outcomes are also influenced by the participation or lack of participation by team members. Course delivery format may be traditional face-to-face, online, or hybrid. The medium of course delivery can also influence course outcomes. Here, we list some important factors that influence students' course outcomes and develop a model to explain and predict course satisfaction.

Student's Course Satisfaction $=$

f (Course Design, Student's Input, Teamwork, Team Size, Class Size, Instructor's Input, Choice of Course Delivery Format, Course Delivery Format, Course Length).

- Course design. Course design can range between poorly designed to extremely well designed.

- Student's input. A student's input can range between no participation to high participation.

- Teamwork. Team members' inputs can vary from one student to another, and from week to week, and can favorably or adversely affect other team members' performance. Teamwork would be a bigger challenge in online setting than in a traditional face-to-face setting.

- Team size. The size of a team can be very important in learning outcomes. Very large teams would find it difficult to collaborate. 
- Class size. Class size plays a very important role in course outcomes. Large classes would be more difficult to manage for the instructor and will adversely affect course outcomes for the instructor and students. A large class size may force an instructor to make large teams thus adversely affecting team performance.

- Instructor's input. An instructor's input can range between limited participation to high participation.

- Choice of course delivery format. Students may or may not have the option of selecting the type of course (a traditional face-to-face, online, or a hybrid). If students have a choice to select a course with their preferred delivery format, then, they are more likely to have higher course satisfaction.

- Course delivery format. A particular course would be traditional face-to-face, online or a hybrid. Some students may prefer one delivery format, while others would prefer a different delivery format, therefore, it is difficult to generalize which delivery format would lead to higher student satisfaction with the course.

- Course length. Course length may vary from the traditional 16 week course, to 8 weeks, to 7 weeks, to 5 weeks, etc. Some students would prefer the longer courses over shorter courses due to various reasons. However, for these courses to be comparable, the same amount of material will have to be covered in a given time period making shorter courses more intensive and demanding courses.

- A student's course satisfaction. A student's course satisfaction is influenced by all of the above factors.

- It is reasonable to assert that a student's course satisfaction is positively influenced by course design, student's contribution, and instructor's contribution, and inversely influenced by the team size, and class size.

- Online students are more likely to prefer individual work over teamwork compared with those in a traditional face-to-face format.

- It is difficult to generalize student's course satisfaction regarding the course delivery format, since students' preferences vary by delivery format. Some students prefer a seated course, while others prefer an online course. This delivery format may vary by course as well. A student may prefer one course in a seated format and another in an online format. If the most preferred course delivery format is not available, then, a particular student may enroll in a less preferred delivery format, but is likely to be somewhat dissatisfied due to being unable to choose his/her best option.
- It is almost impossible to conduct a true experiment by randomly assigning students to various course delivery formats, since students typically self-select the course formats in any semester. Students typically self-select the course delivery format that they most prefer, if such a choice is available.

\section{Case study: MKT 640 Marketing Management course}

Here, we present the design and teaching of a graduate Marketing Management course in the MBA program of a private US University. The course requirements and tools and techniques used to enhance teaching and students' learning are also described here. Sample guidelines, templates, and assessment rubrics are presented in tables at the end of this article. These templates and assessment rubrics for within team discussion and assignments are based on Chernev (2014). We also present students' views about enhancing this course. Thirty-one students enrolled in this course in summer 2016, and they were divided into four teams. Twenty-threestudents completed this course while eight students dropped out.

\subsection{Course description:}

- MKT 640 Marketing Management (3 semester hours) -7 weeks

- This course introduces the marketing perspective on strategy development, the elements of marketing analysis, and the functional decision areas of the marketing manager including products and product lines, pricing policies, branding, promotion and advertising, and channels of distribution. Topics include customer behavior evaluation, value assessment, market segmentation, targeting, and positioning; how to gain and sustain competitive advantages, how to monitor marketing performance and customer satisfaction, and how to develop and implement marketing plans. Prerequisite: BUS 500 Business Essentials (grade of " $B$ " or better).

\subsection{Required materials:}

- Chernev, A. (2014). The marketing plan handbook (4th ed.). Chicago, IL: Cerebellum Press. ISBN: 978-1-936572-39-7 List price: \$27.95 (paperback). Alexander Chernev websites: (http://www.chernev.com/books/) and (http://www.kellogg.northwestern.edu/faculty/dire ctory/chernev_alexander.aspx/)

- Kotler, P. \& Keller, K.L. (2016). Marketing management (15th ed.). New York, NY: Pearson. ISBN: 978-0-13-385646-0. Required chapters 1-3, 5, 6, 9-11, 13-17, 19, and 23. 


\subsection{Recommended materials:}

- Mackey, John and Raj Sisodia. (2013). Conscious capitalism: Liberating the heroic spirit of business. Boston, Massachusetts: Harvard Business Review Press. ISBN: 978-1-4221-44206 . Read this book along with the required reading of chapter 23 "Managing a Holistic Marketing Organization for the Long Run" in Kotler, P. \& Keller, K.L. (2016). Marketing management (15th ed.).

- Recommended chapters are 4, 7, 8, 12, 18, 20, 21, and 22 in Kotler, P. \& Keller, K.L. (2016). Marketing management (15th ed.). New York, NY: Pearson. ISBN: 978-0-13-385646-0.

\subsection{Course grade calculation:}

The course grade is based on five exams, and numerous assignments.

- Exams: There are five exams, each is based on three different chapters from Kotler \& Keller's Marketing Management textbook.

- Axa Assignments (within team discussion). These assignments are about students' marketing plans. The students are grouped into teams at the start of the semester. As a weekly assignment, students work within their teams during Mondays through Fridays to write a section of their marketing plans. Team leaders submit these weekly assignment reports to their instructor for feedback and grading. Students are guided by templates and assessment rubrics for each assignment and for their overall marketing plans that are due in the last week of the semester. The instructor provides feedback on these reports within a couple of days after receiving them.

- A1a. Formation of teams by the instructor at the start of the semester (no grade).

- A1b. Marketing Plan topic selection (no grade).

- A2a. Marketing Plan topic revision.

- A3a. Situation Analysis.

- A4a. Goals, Objectives, and Benchmarks.

- A5a. Marketing Strategy.

- A6a. Marketing Tactics (Marketing Mix).

- A7. Marketing Plan Reports.

- A8. Team Leadership.

- AXc Assignments (across team discussion). Team leaders also share the above assignment reports with other teams in this course. Students then help other teams to improve their plans and also defend their own marketing plans. These across team discussions take place on Saturdays and Sundays. There are five such across team discussions.

\subsection{Calculation of overall course grades:}

- Each week, students need to make a significant contribution to their knowledge and demonstrate their learning.

- Each exam is worth $6 \%$ of the course grade, each weekly team assignment report (AXa) is worth $6 \%$ of the course grade, $5 \%$ for team leadership, and $2 \%$ for each across group discussion (AXc). The final Marketing Plan report is worth $25 \%$ of the course grade.

\subsection{Accelerated course:}

- This is an accelerated 7-week course.

- Each week, students need to make a significant contribution to their knowledge and demonstrate their learning.

\subsection{Assignments and marketing plan:}

- The course syllabus describes the assignments and the term project. The various assignments are sections of the Marketing Plan.

- Students should select/assign coordinators for each assignment and the Marketing Plan. Assign one coordinator for each assignment and two coordinators for the Marketing Plan.

- Assignments and Marketing Plans are group reports. The group coordinator for each week will assign tasks and deadlines to group members, combine their work into a cohesive report and submit it in Moodle course shell by the due date.

- The weekly assignment reports should not exceed eight pages, including everything, and should be uploaded into Moodle by their deadlines.

- The Marketing Plan reports should not exceed 35 pages, including everything, and should be uploaded into Moodle in Week \#7.

- The wikis and forums in Moodle are important for team collaboration to write the weekly assignment reports.

- An assignment report should be revised a few times and edited before it is submitted in Moodle.

- The team leader should submit the assignment report by the due date in Moodle.

- Only one assignment report is required for each team.

- An assignment report must be posted in the appropriate forum in Moodle by the due date in order to be graded.

- A report that is late, posted in a wrong place in Moodle, or e-mailed to the instructor will not be graded. 
2.9. Assign a team leader to each section of the marketing plan report by week 1 :

- The instructor provides a template of suggested leader assignments at the start of the course.

- A team can modify this template by indicating leaders for each AXa assignment or section of the marketing plan. Students submit this leader assignment in an appropriate forum on the first day of class.

- Teams can modify their leader assignments during the semester when there is attrition or poor performance. Teams should keep their instructor and relevant others informed about these changes.

\section{A student team's perspective of the course}

This section describes how a team of eight students (team A) worked week-by-week, as it developed its Marketing Plan. What strategies did the team use to be effective and what else the team members could have done to improve the quality of participation and team output? These suggestions should be helpful for future teams to help enhance their teamwork.

The goal for the MKT 640 Marketing Management course was to write, during seven weeks, a marketing plan for a company selected by team A. To complete this task, the team worked on different assignments each week and posted a weekly report as a specific section of the marketing plan. In order to complete this task, the team members selected leaders for the weekly AXa assignments and provided this list to the professor. These leaders had the responsibility to assign tasks to team members and to write the final report. In addition, the leader provided an evaluation form (see Table 6) to the professor if any of the members did not perform according to the guidelines. The same leader was in charge of weeks one and two, but there were three leaders for separate assignments in week 7 .

The group assignment reports were due on the Friday of each week. Below is a description of the team's collaboration for each week, a list of the most relevant challenges that the team encountered, and some suggestions to help teams to become more productive.

\subsection{Week 1: write a marketing plan topic} proposal. In week one, the team had three assignments:

- Assignment 1a. Introductions and Team Formation.

- Assignment 1b. Marketing Plan topic proposal based on within team discussion.

- Assignment 1c. Marketing Plan topic proposal discussion across teams.
The professor had provided several questions to guide the team's development of a marketing plan topic proposal. In order to complete the information required, the leader for this week distributed the questions evenly into the eight members of the team. In addition, team A's members had the responsibility to read the material and follow the guidelines suggested by the professor. Each member posted the answers for the questions assigned in the discussion forum. Since the first report needed to be submitted by Friday, the leader established Wednesday as the deadline to complete all the tasks. Once the leader received all the information from the team members, he/she was in charge of analyzing the information provided, writing the marketing report, and submitting this document to the professor. Moreover, the leader had the responsibility to post this document in a discussion forum where other teams had the opportunity to analyze and evaluate the report, as well as make any suggestions to improve team A's marketing plan. Furthermore, team A's members had the responsibility to answer all the questions asked by other teams and analyze two other teams' marketing plan topic proposals. The key tool for the success of this week's assignment was to have internal deadlines and keep an active communication among team members through the discussion forums.

There were some challenges during this week such as the leader was trying to have everyone to participate and vote for the best product and company option for marketing plan topic. Nevertheless, the voluntary participation idea was not working and the professor suggested assigning the questions to each one of the team members, listing their names and providing a deadline for their individual post. Having voluntary participation and voting process is important for teams to feel that they are treated fairly. However, since the teams were too big, it was very difficult to find unanimous ideas in a short time. Therefore, in order to improve this week's assignment report, the leader should have delegated the tasks along with deadlines, as soon as the week started.

- One of the biggest challenges for week one was to choose the company and the product to be analyzed for the marketing plan. Since everyone had different ideas, it was a long process to decide what the team really wanted to do. In addition, it was very challenging to get every team member to agree when choosing a company and a product. Therefore, as a suggestion, the professor could provide a list of company names and let the teams select a company from this list then decide what product or service they should analyze for their Marketing Plans. 
- The second challenge this week was to get every member to review the proposal before it was submitted on Friday. There was a deadline for each member to make changes in the draft. However, some of the team members requested to provide their feedback after the deadline. The leader accommodated these requests but had less time to synthesize their input to produce a cohesive final report. This leader performed better by setting deadlines for the second assignment (in week 2) to prevent late submissions by team members.

3.2. Week 2: revise the marketing plan topic proposal. This week's assignment had the same list of questions that were answered in week one for the marketing plan. The team leader assigned those questions to team members and required them to improve their answers by conducting research in the light of the professor's and other team members' feedback from the last week. The team members were required to make their individual posts before Wednesday; giving enough time to the leader to summarize the information to write a report and share it with team members for their comments. After getting team members' input and approval, the leader submitted the final report to the professor for review and grading.

3.3. Week 3: write situation analysis report. There were several challenges this week. The team leader was confused and assigned tasks inconsistently to team members. Also, some team members did not read the required sections of the Marketing Plan Handbook before they posted their contributions. Even though, the professor provided important information and comments to guide the team, the team's final assignment report lacked some important information. One solution for this kind of a problem is to create a list of objectives and tasks for the assignment, and assign them to team members. In addition, it is imperative to require team members and the leader to read and follow Chernev's Marketing Plan Handbook and the weekly templates that are based on this Handbook.

3.4. Week 4: write goals, objectives, and benchmarks report. The leader for this week was confused and did not assign tasks to team members consistently. However, the professor helped by assigning tasks consistently to team members. However, the team leader was late in combining and posting team members' contributions in a consistent report. Moreover, the leader needed to post the draft of the report soon enough for all the members to provide comments. This week's assignment report was weak due to poor leadership by this week's designated leader.
3.5. Week 5: write marketing strategy. Team A had to face late assignment of tasks from the leader. Therefore, the professor had to intervene by providing some suggestions to allocate each activity to every member of the team, as well as deadlines that could help with the writing process. Some of the students of this team were confused on the assignments and, therefore, the research was based on general aspects of the company instead of the product selected for the marketing plan. A solution to this type of problems is to emphasize the focus on the product or service being analyzed and not the overall company. Students could have benefited by paying more attention to the templates and the Marketing Plan Handbook. In addition, the team leader should assign tasks with a deadline on the first day of the week. This would give students more time to complete their assigned tasks and they should be able to produce better reports.

3.6. Week 6: write Marketing Tactics (Marketing Mix) report. This week, team A made three subteams to complete the following tasks:

- Write Marketing Tactics (Marketing Mix)
Report
- Implementation
- Control

At this point, the members of each team had a broad knowledge of their product or service, as well as a better understanding of the tasks. The members of every sub-team collaborated actively and efficiently. As a result, Team A obtained one of the highest grades and a positive feedback from the professor.

3.7. Week 7: write Marketing Plan Report (including implementation and control). This week, the biggest challenge was trying to fix, change, and improve the final marketing plan. Team A required its members to fix their own sections using the professor's feedback and the Marketing Plan Handbook. This strategy could have been successful if the members in Team A had actually made the appropriate changes to their sections of the marketing plan report. In contrast, team $\mathrm{C}$ finalized their marketing plan report by making each one of their members in charge of one section of the marketing plan. This strategy helped them to finalize their marketing plan report in less time. Team A, in contrast, had eight people reviewing and modifying the same document, almost at the same time, which became confusing and overwhelming. In order to improve productivity for this kind of assignments, the teams should use collaboration tools such as Google Drive and/or Google Teamwork to post and update their marketing plans. This will give their team members the opportunity to make changes at their convenience. It is also imperative to create a schedule specifying the activities and the person in charge. 
Some students in our team were enrolled in two courses at the same time and they often had limited participation in some of the assignments. Also, some students in our team sometimes focused too broadly on the target company itself instead of focusing more sharply on the target product or service that our team was trying to develop and market. We suggest the following ideas to help improve team productivity and course outcomes:

- Make smaller teams with a maximum of four students per team. For all the teams, it was hard to keep up with all the weekly comments posted by each student. Some weeks, close to one hundred and sixty comments were posted by students and it was difficult to read all of them.

- Require all students to complete and submit the team evaluation forms each week. This will keep the instructor aware of the extent of participation of individual team members so he/she could take timely corrective action.

- Assign team members consistently across weekly assignment subjects. For example, if a team member writes about customers for one assignment, then, each week he/she should stay with the same subject across assignments where appropriate. Thus, students will develop specialized expertise in specific subject areas of a marketing plan and will be helpful in expertly and efficiently writing the final Marketing Plan report.

- Require only one textbook and make all exams from this textbook. This should ensure that everyone understands the information required for writing a good marketing plan.

- The school provided an online team room forum where all the team members could meet at once. Schedule conflicts, however, made it impossible for all eight team members to meet at the same time. However, having a group meeting could be very helpful to make decisions and accomplish goals.

- A vigilant instructor can guide a team, when needed, so the team members could write good assignment reports.

\section{Discussion and conclusion}

It is always a challenge to improve students' course learning outcomes and satisfaction in online graduate courses. Here, the learning outcomes depend upon a lot of factors, as outlined in the
Student Course Satisfaction Model. Based on the above findings, we present here, some guidelines to enhance teaching and course outcomes for a graduate Marketing Management course.

- Develop a comprehensive syllabus and an online course shell.

- An instructor may use a marketing plan or case studies in a graduate Marketing Management course. Here, we assume that the instructor requires a marketing plan as a team project for the course.

- Require a textbook and a marketing plan handbook to guide teamwork.

- Form student teams at the start of the semester and allow students to modify teams, if necessary.

- Require a leader for each assignment, and provide a template and an assessment rubric for each assignment. See Tables $4 \& 5$ which are adapted from Chernev (2014).

- Require teams to carry out team discussion in a forum that is accessible to the instructor, so, it will be available for future course evaluation.

- If requiring across group discussion, then, require team leaders to post their assignment reports in forums for across team discussion.

- Provide an assessment rubric for across team discussion to guide students' participation. The instructor should use this rubric to evaluate individual student's participation in across team discussion. See Table 7 which is adapted from Hazari (2004), Kayler \& Weller (2007) and Alden (2011).

- Provide frequent and timely feedback on each team assignment report.

- The burden of evaluating a lot of assignments may lead some instructors to avoid assessment of individual student's contributions to team projects and assign everyone in a team the same grade. However, this will adversely penalize high performing students and unduly reward poor performers who may be liabilities for their teams.

- The administrators should keep class size manageable and split a course into two, if the class size exceeds a certain reasonable upper limit.

- For many professors, a class size of 30 students will create many challenges like manageable team size for class projects, providing timely feedback on team assignments and projects, and managing team discussion. 


\section{References}

1. Alden, J. (2011). Assessment of Individual Student Performance in Online Team Projects, Journal of Asynchronous Learning Networks, 15(3), pp. 5-20.

2. Chernev, Alexander. (2014). The Marketing Plan Handbook. $4^{\text {th }}$ edition. Cerebellum Press.

3. Dubas, Khalid M., and Strong, James T. (1993). Optimal Course Design Using Conjoint Analysis, Journal of Marketing Education, spring, pp. 31-36.

4. Dubas, Khalid M., Best, Kathy T., Long, Joseph M., Crumpacker, Norman (2016). Enhancing Student Participation and Course Outcomes in Online Graduate Courses, Academy of Educational Leadership Journal, 20(1), pp. 32-49.

5. Favor, J.K. and Kulp, A.M. (2015). Academic Learning Teams in Accelerated Adult Programs, Adult Learning, 26(4), pp. 151-159.

6. Hazari, Sunil. (2004). Strategy for assessment of online course discussions, Journal of Information Systems Education, 15(4), pp. 349-355.

7. Katzenstein, Herbert, Kavil, Sridhar, Mummalaneni, Venkat and Dubas, Khalid (1994). Design of an Ideal Direct Marketing Course from the Students' Perspective, Journal of Direct Marketing, 8(2), pp. 66-72.

8. Kayler, Mary and Weller, Karen. (2007). Pedagogy, self-assessment, and online discussion groups, Educational Technology \& Society, 10(1), pp. 136-147.

9. Kotler, Philip and Keller, K. (2016). Marketing Management. $15^{\text {th }}$ edition. Pearson Publishing.

10. Mackey, John and Sisodia, Raj. (2013). Conscious capitalism: Liberating the heroic spirit of business. Boston, Massachusetts: Harvard Business Review Press. ISBN: 978-1-4221-4420-6. 


\section{Appendix}

Table 1. Responsibilities of team leaders and team members

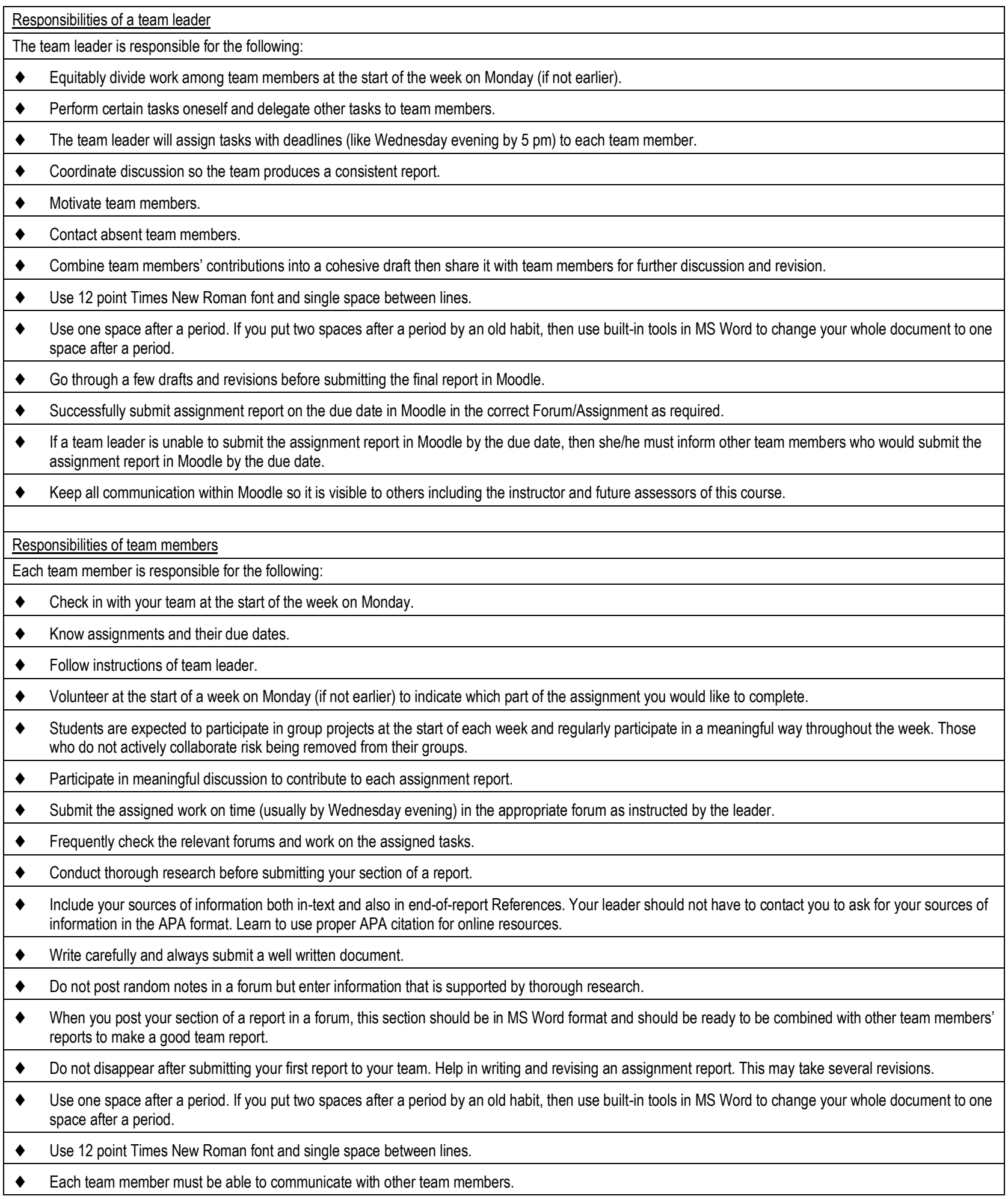


Table 2. Team members' participation and evaluation

Team members' participation and evaluation

- Students will work in teams to complete assignments and a marketing plan.

- A team member can be helpful or harmful for a team. Therefore, team members' evaluations are necessary for those members who do not meet expectations.

- Poorly performing team members often miss classes/meetings/forums, arrive late, leave early, do not communicate well, submit the required work late, or turn in poor quality work, etc.

- Poorly performing team leaders do not assign tasks with deadlines to their team members at the start of a week, communicate poorly, do not combine contributions by team members into a draft report by the middle of the week, do not guide a team to revise their report several times. They submit poorly written, poorly edited, disorganized report, or fail to submit the report on time.

- Each team member can evaluate every other team member for an assignment. Upload (not paste) your team member evaluations in Moodle by the due date of the assignment.

- Harmful team members should be removed from their teams immediately.

- Students can send me an e-mail to tell me about the team member(s) or team leader(s) that should be separated from their teams for poor performance. If two students from a team send me an e-mail requesting to separate a team member/leader, then, I will decide about it.

- I will immediately inform the separated team member(s) about their new status.

- By using a simple majority vote, a group can remove a team member for lack of participation or for submitting work of poor quality.

- Do not wait until the last week to remove poorly performing students. A poorly performing student can harm the whole group by forcing others to do his/her work at the last minute thus lowering the overall quality of the assignment reports.

- The group members should inform their instructor and the removed student(s) about their separation from a group.

- The instructor will create a one-person group for a removed student to work on the remaining assignments and Marketing Plan.

Table 3. Information about assignments and marketing plans

Important Instructions:

- Your Marketing Plan title must be approved by your instructor during the first week of semester.

- Select a large public company that sells stocks. A public company is required to regularly provide its financial information to the SEC and to the public. Find the stock symbol of this company and include it in your topic proposal. Search for your company in http://finance.yahoo.com/. When I enter Microsoft in this URL, I get "Microsoft Corporation (MSFT)," where MSFT is its stock symbol indicating that Microsoft is a public company. I can get financial information about Microsoft from the Investor Relations section of its website at https://www.microsoft.com/en-us/lnvestor/sec-filings.aspx

By submitting this topic, you affirm that:

1. Your Marketing Plan will not utilize sections of a Marketing Plan on this topic that may have been written for another course.

2. You will avoid any and all plagiarism in writing your Marketing Plan.

How to submit your reports.

- Collaborate with your team members to write your assignment reports in Microsoft Word. Your team leader will UPLOAD your weekly assignment reports in the appropriate forum in Moodle. In week \#7, your team leader will UPLOAD your final Marketing Plan report into Moodle by the due date.

- Assignment reports length. Your assignment reports should not exceed 8 pages. Use single space. Use 12 point Times New Roman font. Separate each sentence by one blank space (two spaces between sentences is now out of fashion).

- Substantial. Provide as much detail as is necessary to write your reports.

- Substance. Your written report should be substantive. Substance is more important than the length of your report.

- Formatting and readability. You should write clearly and properly format your report. Where necessary, use headings and subheadings to improve readability. Make sure that your report does not become one large paragraph without any formatting and breaks between sections because such a report will automatically receive a score of $25 \%$ or lower.

- Citations. Any information that does not originate from you must be appropriately cited in the body of your report and at the end in references. Follow the APA style for citations.

- Proofread. Remove all spelling and grammatical mistakes.

- Reports that will NOT be graded. Late reports, reports posted at the wrong place in Moodle, or reports e-mailed to your instructor will not be graded.

- Thirty minutes wait. You can edit your post in Moodle within 30 minutes after posting it (unless the deadline is within 30 minutes).

- Reading other students' reports. Other reports become visible 30 minutes after you post your report.

- Syllabus. Refer to your syllabus for detailed instructions about your assignments.

- Assessment rubric. As a group, complete the assessment rubric for your assignment and attach it as the last page of your assignment report. Your team leader for the assignment will upload this combined report into Moodle as required. 
Table 4. Marketing strategy (target market and value proposition)

Template [refer to Chernev (2014). Chapter 7 strategy and appendix A. The Positioning Statement.]

[The team leader will assign each of the following sections to one or more students. A suggested assignment is indicated below. Depending upon the group size, however, the team leader can assign multiple students to a section or multiple sections to a student.]

Develop a marketing strategy:

Define the master plan that is designed to achieve the company's goals. There are two key components of this strategy: the offering's target market and value proposition. [The team leader will write one or two opening sentences here; the details belong below.]

\subsection{Target market}

Identify the offering's target market—customers, collaborators, the company, competitors, and context-in which the company will launch its new offering. Identify the value proposition and positioning statements for these stake holders. An action plan for designing, communicating, and delivering value in each of the already identified target markets will be developed in the next section titled Marketing Tactics. [The team leader will write two or three opening sentences here; the details belong to specific sections below.]

1.1.1. Customers [assign this section \& 1.2.1. Customer value to student \#1 who previously wrote this section for A3a Situation Analysis report]

Define the need(s) to be fulfilled by the offering and identify the distinguishing characteristics (i.e., profile) of customers with such needs. Write each customer segment under a different subheading. Describe demographic and behavioral characteristics of each customer segment.

1.1.2. Collaborators [assign this section \& 1.2.2. Collaborator value to student \#2 who previously wrote this section for A3a Situation Analysis report]

Identify the key collaborators (e.g., suppliers, channel members, and communication partners) and their strategic goals. Write each major collaborator type under a different subheading. Use bullet points for clarity and concise presentation.

1.1.3. Company [assign this section \& 1.2.3. Company value to student \#3 who previously wrote this section for A3a Situation Analysis report]

Define the strategic business unit responsible for the offering, the relevant personnel, and key stakeholders.

1.1.4. Competitors [assign this section to student \#4 who previously wrote this section for A3a Situation Analysis report]

Identify the competitive offerings that provide similar benefits to target customers and collaborators. Write each major competitive offering under a different subheading or bullet point. Organize this information in a table that will include your offering as well.

1.1.5. Context [assign this section to student \#5 who previously wrote this section for A3a Situation Analysis report. Here you will focus on the context for your proposed offerings.]

Evaluate the relevant economic, technological, sociocultural, regulatory, and physical context.

1.2. Value proposition

Define the offering's value proposition and positioning to target customers, collaborators, and the company. Use the 3-V principle of managing value to create optimal value proposition. Identify the primary source of value or the most important benefit that the company wants to be associated with. Also, identify the reference point or benchmark to define the value of the offering. This benchmark could be non-comparative (the reference point is a particular customer need and not any competitive offering) or comparative (the reference point is a competitive offering). [The team leader will write three or four sentences here; the details belong below.]

1.2.1. Customer value and positioning statement [assign this section to student \#1 (see above)]

Define the offering's value proposition, positioning strategy, and positioning statement to target customers. Use subheadings to label each subsection. Refer to "Appendix A. The Positioning Statement" (Chernev, 2014) for details.

1.2.2. Collaborator value and positioning statement [assign this section to student \#2 (see above)]

Define the offering's value proposition, positioning strategy, and positioning statement to collaborators. Use subheadings to label each subsection. Refer to "Appendix A. The Positioning Statement" (Chernev, 2014) for details.

1.2.3. Company value and positioning statement [assign this section to student \#3 (see above)]

Define the offering's value proposition, positioning strategy, and positioning statement to company stakeholders/personnel. Use subheadings to label each subsection. [Simply creating value for the customer is not sufficient. A company must capture value as well in terms of increased sales revenue, higher profit, more name recognition, increased loyalty, higher good will, etc.] Refer to "Appendix A. The Positioning Statement" (Chernev, 2014) for details.

1.3. Overall Positioning Statement. This is a succinct summary of an offering's strategy. It should include: (1) an offering's target customers, (2) the frame of reference (non-comparative or comparative) used by customers to evaluate the offering, and (3) the primary reason for customers to buy the offering. [The team leader will write this statement in collaboration with other team members. Refer to "Appendix A. The Positioning Statement" (Chernev, 2014) for details]. 
Table 5. Assessment rubric for assignment \#5a: Marketing strategy (target market and value proposition)

Developing a Marketing strategy: Chernev, 2014, Ch. $7 \&$ appendix A.. Define the master plan that is designed to achieve the company's goal. There are two key components of this strategy: the offering's target market and value proposition.

Assessment by instructor:

Course: MKT 640 Marketing Management. Group name:

The desired outcome that the company is trying to achieve.

Evaluation Scale: A (Excellent $)=93-100$, A- $=90-92, \mathrm{~B}+(\mathrm{Good})=87-89, \mathrm{~B}=83-86, \mathrm{~B}-=80-82, \mathrm{C}+($ Fair $)=77-$ $79, \mathrm{C}=70-76, \mathrm{D}($ Poor $)=60-69$, and $\mathrm{F}($ Not Acceptable $)=0-59$.

\begin{tabular}{|l|l|l|l|}
\hline \multicolumn{1}{|c|}{ CATEGORY } & \multicolumn{1}{|c|}{ Description } & $\begin{array}{c}\text { Assessment by } \\
\text { team }\end{array}$ & Assessment by instructor \\
\hline 1. Target market. & $\begin{array}{l}\text { There are five key factors (use the 5-C framework) target customers, } \\
\text { company, collaborators, competitors, and context. Develop a master plan to } \\
\text { achieve the company's goals. Define the offering's target market and the } \\
\text { offering's value proposition. }\end{array}$ & & \\
\hline a. Target customers. & $\begin{array}{l}\text { Identify target customers and strategies to reach them. } \\
\text { Define the need(s) to be fulfilled by the offering and identify the distinguishing } \\
\text { characteristics (i.e., profile) of customers with such needs. Write the } \\
\text { demographic and behavioral characteristics of each target customer segment. }\end{array}$ & & \\
\hline b. Other four factors. & $\begin{array}{l}\text { Describe the role of the company (business unit responsible for the offering), } \\
\text { collaborators, competitive, and context overview. }\end{array}$ & & \\
\hline 2. Value proposition. & $\begin{array}{l}\text { Indicate the value that is created by the company's offering for the relevant } \\
\text { market participants: customer value, company value, and collaborator value. } \\
\text { Use the 3-V principle of managing value to create optimal value proposition. }\end{array}$ & & \\
\hline a. Primary source of value. & $\begin{array}{l}\text { Identify the primary source of value or the most important benefit that the } \\
\text { company wants to be associated with. }\end{array}$ & & \\
\hline b. The reference point. & $\begin{array}{l}\text { Identify the reference point or benchmark to define the value of the offering. } \\
\text { This benchmark could be non-comparative (the reference point is a particular } \\
\text { customer need and not any competitive offering) or comparative (the reference } \\
\text { point is a competitive offering). }\end{array}$ & \\
\hline 3. Positioning statement. & This is a succinct summary of an offering's strategy. & \\
\hline a. Target customers. & The offering's target customers. & \\
\hline b. The frame of reference. & $\begin{array}{l}\text { The frame of reference used by customers to evaluate the offering. This could } \\
\text { be non-comparative or comparative. }\end{array}$ & \\
\hline c. The key source of value. & The primary reason for customers to buy the offering. & \\
\hline
\end{tabular}

Table 6. Team evaluation form

\begin{tabular}{|l|}
$\begin{array}{l}\text { Instructions:Enter the names of your teammates in the table below then rate their participation in the assignment between } 0 \text { and } 10 . \text { Give a } 10 \text { to those team } \\
\text { member who met or exceeded expectations.Give a lower score to those who did not do their full share of the work. For example, a rating of } 5 \text { indicates that the } \\
\text { team member did half the amount of expected work. A rating of } 0 \text { indicates that the team member did not contribute to the project. Do not rate yourself. Save this } \\
\text { form with your name in the file name as joe_team_evaluation and submit it to your instructor by the due date. }\end{array}$ \\
\hline \\
\hline Assignment: \\
\hline Your name: \\
\hline Team leader:_ \\
\hline Team name: \\
\hline Teammate name $\quad$ Rating $(0-10)$ \\
\hline 1. \\
\hline 2. \\
\hline 3. \\
\hline 4. \\
\hline 5. \\
\hline 6. \\
\hline 7. \\
\hline
\end{tabular}


Table 7. A rubric to assess students' participation in online across group discussion on assignments

This rubric is intended to guide students' participation in across group discussion in assignments labeled AXc during Saturdays and Sundays. Here, students help other teams to improve their reports. Students do not turn in any evaluation of across group discussion by their peers. Instead, this rubric is used by your instructor to evaluate students' participation in across group discussion. Table 7 is adapted from Hazari (2004), Kayler \& Weller (2007) and Alden (2011).

\begin{tabular}{|c|c|c|c|c|}
\hline \# & Items & Poor & Good & Excellent \\
\hline 1 & Posted main topic (assignment under discussion) information only. & $\mathrm{X}$ & & \\
\hline 2 & Posted main topic information and more than one response. & & $X$ & $\mathrm{X}$ \\
\hline 3 & No depth of presentation, no research base, opinion only. & $\mathrm{X}$ & & \\
\hline 4 & Comments were barely related to main discussion question and/or other student posting. & $\mathrm{X}$ & & \\
\hline 5 & No constructive comments to help class discussion. & $\mathrm{X}$ & & \\
\hline 6 & Postings were poorly written. & $\mathrm{X}$ & & \\
\hline 7 & Posted within a couple of hours of the deadline. & $\mathrm{X}$ & & \\
\hline 8 & Posted at least twice per week. & & $x$ & $x$ \\
\hline 9 & $\begin{array}{l}\text { Responses were not limited to "I agree" or "great idea" but were supported with examples from } \\
\text { personal and professional experiences. }\end{array}$ & & $X$ & $X$ \\
\hline 10 & $\begin{array}{l}\text { Postings demonstrated a knowledge and understanding of assigned readings from both textbooks } \\
\text { (Kotler \& Keller and Chernev). }\end{array}$ & & $X$ & $x$ \\
\hline 11 & Referenced other research, gave examples, and evoked follow-up responses from other students. & & $X$ & $x$ \\
\hline 12 & $\begin{array}{l}\text { Enhanced quality of discussion (i.e., illustrated a point with examples, suggested new perspectives on } \\
\text { issues, asked questions that helped further discussion, cited current news events etc.) }\end{array}$ & & $X$ & \\
\hline 13 & $\begin{array}{l}\text { Substantially enhanced quality of discussion (i.e., illustrated a point with examples, suggested new } \\
\text { perspectives on issues, asked questions that helped further discussion, cited current news events, } \\
\text { etc.) }\end{array}$ & & & $X$ \\
\hline 14 & $\begin{array}{l}\text { Replied to several other student postings and provided relevant responses and constructive feedback } \\
\text { to the student. }\end{array}$ & & $x$ & \\
\hline 15 & $\begin{array}{l}\text { Replied to several other student postings on a regular basis and provided relevant responses and } \\
\text { constructive feedback to the student posting. }\end{array}$ & & & $x$ \\
\hline 16 & Postings were well-written, incorporating proper grammar, spelling, and sentence structure. & & $X$ & $X$ \\
\hline 17 & Postings substantially helped the target group to write a high quality assignment report. & & $X$ & $\mathrm{X}$ \\
\hline 18 & $\begin{array}{l}\text { Postings utilized not just business periodicals but peer-reviewed scholarly articles with proper citations } \\
\text { (using both in-text citations and end of posting citations in the APA format). }\end{array}$ & & $X$ & $X$ \\
\hline 19 & Read and considered substantial number of student postings before responding. & & & $X$ \\
\hline 20 & Demonstrated leadership in discussions. & & & $\mathrm{X}$ \\
\hline
\end{tabular}


Table 8. Selected students' comments on different aspects of MKT 640 Marketing Management course

Explanation of information in this table: In each section below, the instructor's questions are in italic, and they are followed by a sample of student's remarks.

Request permission to share your marketing plans with future students:

I would like to request your permission to use your Marketing Plans to guide future students.

I give you permission to use our Marketing Plan to guide future students.

Provide comments to improve this course:

I would also like to request that each of you take a few minutes of your time to provide comments to help improve this course for future students. This reflective assessment should be helpful to you as well.

I think the most disappointing thing for me was that our final grade for the marketing plan was not reflective of the grades we received each week on each individual piece of the marketing plan. Otherwise, I think this class is a wonderful opportunity to think outside of the traditional class "box" and actually come up with a marketing plan. This could prove to be beneficial in the future in someone's career because they have that experience from this class.

\section{Workload:}

We covered 15-weeks of coursework in 7 weeks. Do you think that the course workload was manageable in 7 weeks?

I feel that the workload was manageable in the 7 weeks course. It was challenging, which is understandable in a Master's program. I thoroughly enjoyed taking this class.

\section{Textbooks:}

What are your thoughts about the textbooks: Marketing Management by Kotler \& Keller and Marketing Plan Handbook by Chernev.

I really enjoyed reading through the Marketing Plan Handbook by Chernev. It was very useful in giving additional explanation for different sections of the marketing plan. The Marketing Management book was a good textbook as well. It wasn't a difficult read to get through.

Templates and rubrics for assignments and marketing plan:

Chernev had provided the two templates for marketing plans (one for a new offering and one for an existing offering). Using his Handbook, I had developed the templates and rubrics for each assignment and also for the overall marketing plan to guide your work.

Having the templates and rubrics to know the requirements and the grading scale was an added tool that was much appreciated. The templates gave information on what each section of the marketing plan required which I found very helpful.

\section{Marketing Plan:}

This course is primarily oriented towards writing a marketing plan. Should this course continue to require students to develop a marketing plan or should there be some other assignments or activities but no marketing plan write up?

I personally enjoyed writing the marketing plan. It was challenging, but I enjoy challenges. I also was very fortunate that I had a wonderful team to work with and everyone did above and beyond each week to ensure that we got our work completed. I had never written a marketing plan before so it was a new experience and I think, for me, to actually go through the steps of writing a marketing plan helped me learn more about the marketing process than completing other activities.

\section{Exams:}

There were 15 chapters from Kotler \& Keller's Marketing Management book and there were five exams in this course. Should I include additional chapters and exams? Were the number of chapters per exam sufficient? Were the number of questions per exam sufficient? Was the level of difficulty of questions on the exams appropriate?

The exams were sufficient and touched on important aspects from each chapter. I wouldn't think that there would need to be any additional chapters or exams/exam questions.

\section{Online discussion forums:}

What about online discussion forums? I have provided you a rubric to guide online discussion across groups. I was pleased with the quality of across group discussion. What are your thoughts about within group and across group discussion? How helpful was the online discussion rubric? How can I improve upon this rubric for future students? Any ideas for improving the online discussion forums?

I felt that the online discussion forums went extremely well. Personally from a standpoint of my group, I really appreciated someone else looking over each section and making critiques because when you work on a paper, you are no longer objective when it comes to reading through the material. A fresh set of eyes reading through and asking questions really aided us in our report.

\section{Student collaboration:}

Any ideas for improving student collaboration?

I don't think that you as an instructor can force students to collaborate. Some students are just at their very nature slacker than others. They will do the bare minimum to get by and do nothing else. 